\title{
STAT6 - polymorphisms, haplotypes and epistasis in relation to atopy and asthma
}

\author{
Marek Godava, Radek Vrtel, Radek Vodicka
}

\begin{abstract}
Background. STAT6 has an important role in the IL-4 / IL-13 signalling pathway. Genome - wide association studies have shown that particular polymorphism (SNP) or haplotype variants of STAT6 as well as epigenetic gene modifications are associated with IgE level and asthma in childhood.

Methods. A review of the available literature was performed to map out the function and signalling pathway of STAT6, studies of STAT6 SNPs association with susceptibility to asthma and atopy, covering the years $1997-2012$ were summarized, and the value of epigenetic and epistatic influences on STAT6 and their relevance to the development of the studied phenotype (atopy or asthma) were determined.

Results. There are 2 SNPs (rs71802646 and rs320411) with clinical association and proven functional effect on STAT6 expression. The effect of STAT6 SNPs cumulates in haplotypes and more potently during interaction with SNPs in the genes from the signalling pathway (IL4, IL4Ra, and IL13). Expression of STAT6 is also influenced by DNA methylation. Atopy is traditionally believed to be maternally inherited but there is one report about paternally overtransmitted STAT6 haplotype (TCA haplotype, built from rs324011, rs3024974 and rs4559 SNPs).

Conclusions. STAT6 polymorphisms and their combinations have an important influence on lgE level and development of asthma. However, the interaction between SNPs in the IL-4 / IL-13 signalling pathway is of greater impact. Hypermethylation of the STAT6 promoter is also significant in the regulation of STAT6 expression and this fact opens possibilities for targeting therapy in asthma.
\end{abstract}

Key words: IgE, atopy, asthma, polymorphisms, haplotypes, STAT6, epistasis

Received: November 11, 2012; Accepted with revision: May 27, 2013; Available online: June 6, 2013 http://dx.doi.org/10.5507/bp.2013.043

Department of Medical Genetics and Fetal Medicine, Faculty of Medicine and Dentistry, Palacky University Olomouc and University Hospital Olomouc, Czech Republic

Corresponding author: Marek Godava, e-mail: GodavaM@seznam.cz

\section{INTRODUCTION}

Allergic diseases, such as asthma, atopic dermatitis and hay fever, are associated with atopy ${ }^{1}$. The main feature of atopy is elevation of IgE level, which occurs after IL-4 stimulation and ligation of CD40 ligand to CD40 that is required for isotype switching to $\operatorname{IgG} 1$ and $\operatorname{IgE}\left(\right.$ ref. $\left.^{2}\right)$. The high occurrence of atopy in families implies that genetic factors have an important role in its control. Several papers have reported significant association of maternal atopy with elevated cord blood IgE level and some followup studies have suggested that an elevated IgE level is a good marker for prediction of early atopy onset, better than maternal atopy ${ }^{3-5}$. Canfield et al. ${ }^{6}$ showed a strong association of parent's total IgE level (both maternal and paternal) with elevated total IgE levels in 4-year old children; in addition, specific IgE levels in children were associated with their mother's specific IgE levels. Cookson et al. ${ }^{7}$ linked the $11 \mathrm{q} 13$ locus with maternally transmitted atopy. Genome wide association analysis (GWAS) of total $\operatorname{IgE}$ level on a population of children with asthma in Costa Rica revealed modest linkage with $7 \mathrm{p} 15$ for both genders and significant association with the 20q12 locus in boys. Subsequent analysis found two of the $J A G 1$ polymorphisms to be significantly associated with total IgE in males ${ }^{8}$. Weindiger's et al. ${ }^{9}$ GWAS found FCER $1 A$ to be another locus for susceptibility to elevated IgE levels.

The central pathways for IgE production are orchestrated by IL-4 and IL-13 and their shared receptor. The cytokines are located on $5 \mathrm{q} 31$ - a region repeatedly linked with atopy and asthma ${ }^{10-13}$. Total IgE level has been also shown to be influenced by the $12 \mathrm{q}$ locus ${ }^{1416}$. This locus contains, among others, the gene for STAT6 which is signalling downstream of the IL-4/13 receptor. STAT6 is one of the most common candidate genes associated with $\mathrm{IgE}$ level and asthma in childhood. To search for publications on polymorphisms and haplotypes of STAT6 and their relation to the level of IgE, we scanned pubmed using the key words: STAT6, polymorphisms, haplotypes, IgE, asthma, atopy interaction, maternal, paternal, parental and inheritance. These papers spanned years 1997 - 2012.

\section{Structure of the STAT6 and its product}

STAT6 was successfully identified and cloned for the first time by Hou et al. ${ }^{17}$ and independently by Quelle et al. ${ }^{18}$. The gene maps to $12 \mathrm{q} 13.3$-q14.1, encompasses over $19 \mathrm{~kb}$ and consists of 23 exons $^{19}$. The first two and part of third exons belong to 5 ' UTR (untranslated region) and a large part of the last exon is untranslated as well (Fig. 1). STAT6 gives to rise to several mRNA isoforms: STAT6 


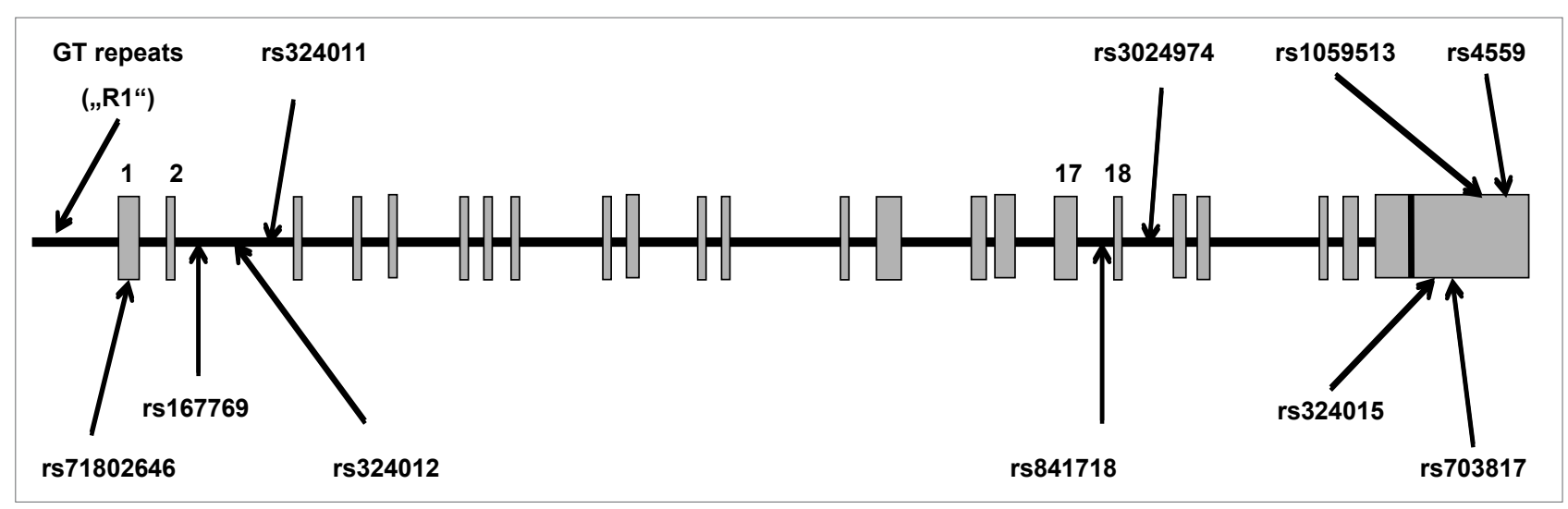

Fig. 1. Structure of STAT6. The STAT6 gene contains 23 exons. Localization of polymorphisms reviewed in this article is depicted according to their position in the gene.

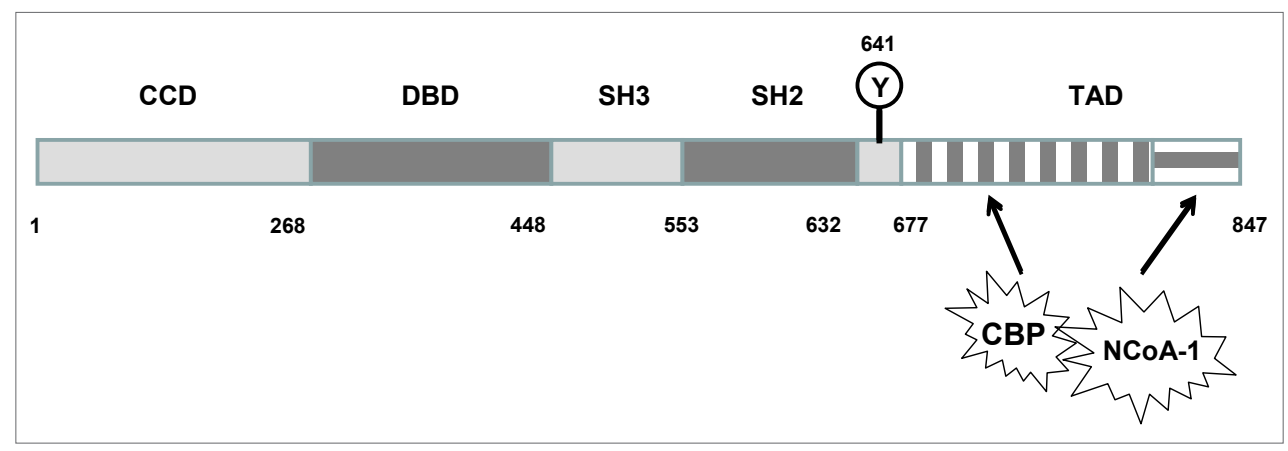

Fig. 2. Structure of STAT6. CCD - coiled coil domain (N - terminal domain), DBD - DNA binding domain, SH3 - Src Homology 3 domain, SH2 - Src Homology 2 domain, Y - tyrosine residue, TAD - transactivation domain; CBP and NCoA-1 - coactivators of STAT6; numbers mark position of amino residues.

(assembled from all of the exons), STAT6a (missing part of the 3 'UTR), STAT6b (missing exon 4), STAT6c (part of the exon 16 is included into intron) (ref. ${ }^{20-22}$ ). Finally, there are 2 isoforms created by intron retention: in addition to exonic regions, STAT6d is made up of intron 17 and STAT6e contains introns 17 and 18 (ref. ${ }^{23}$ ).

STAT6 shares structural similarity with the other STAT proteins (Fig. 2) and is composed of the N-terminal domain (coiled coil domain), DNA binding domain (DBD), SH3- like domain, SH2 domain and transactivation domain (TAD) (ref. $\left.{ }^{24}\right)$. The N-terminal domain is composed of 8 helices showing coiled coil structural motif. The first 130 amino acids are conserved among all of the STAT proteins and this part of the protein has an important role in dimer - dimer interactions, tetramerization of STAT dimers and consequently cooperative DNA binding ${ }^{25,26}$. The region of the DBD is highly conserved amongst the STATs and serves for binding of specific GAS sequences ${ }^{25}$. SH3 domains are generally known as "Molecular Velcro" because of their ability to interact with proteins having a proline - rich region ${ }^{27,28}$. The conserved Src homology 2 ( $\mathrm{SH} 2$ ) domain has the ability to associate with cytokine receptor and interact with phosphotyrosine - containing proteins, thus dimerizes with the other STAT and influences DNA binding ${ }^{29,30}$. The TAD has two distinct regions, the presence of both of them is important for transactivation. The N-terminal interacts with CBP (CREB-binding protein) and the distal C-terminal interacts with NCoA1 (nuclear receptor coactivator 1 , a member of the $\mathrm{p} 160 / \mathrm{SRC}$ coactivator family) - specific STAT6 coactivator ${ }^{31}$.

\section{STAT6 function and signalling pathway}

STAT6 was initially identified as a transcription factor induced by IL-4 signalling ${ }^{17}$ and it was suggested that activation of STAT6 is required in IL-4 promoted IgE isotype switching ${ }^{32}$. Next, the physiological role of STAT6 was assessed on animal models. Stat6 null mice were viable; however, they were unable to undergo class switching to $\mathrm{IgE}$ antibodies. Additionally, they were unable to upregulate IL-4 responsive gene in B cells and their T cells failed to acquire $\mathrm{T}_{\mathrm{H} 2}$ phenotype in response to IL-4 (ref. ${ }^{33,34}$ ).

IL-4 may signal through two receptors - type I is composed of IL-4R $\alpha$ and $\gamma c$ subunit and in type II, the IL-4R $\alpha$ associates with IL-13a. The type I complex is expressed predominantly in hematopoietic cells and binds specifically to IL-4 only. After IL-4 binding, the subunits of the receptor dimerize, bringing the JAK kinases associated with the receptor (JAK1 with IL-4R $\alpha$ and JAK3 with $\gamma$ c subunit) in close vicinity (Fig. 3). This leads to their auto- or cross-phosphorylation. Activated JAKs then phosphorylate specific thyrosine residues in the cytoplasmatic 


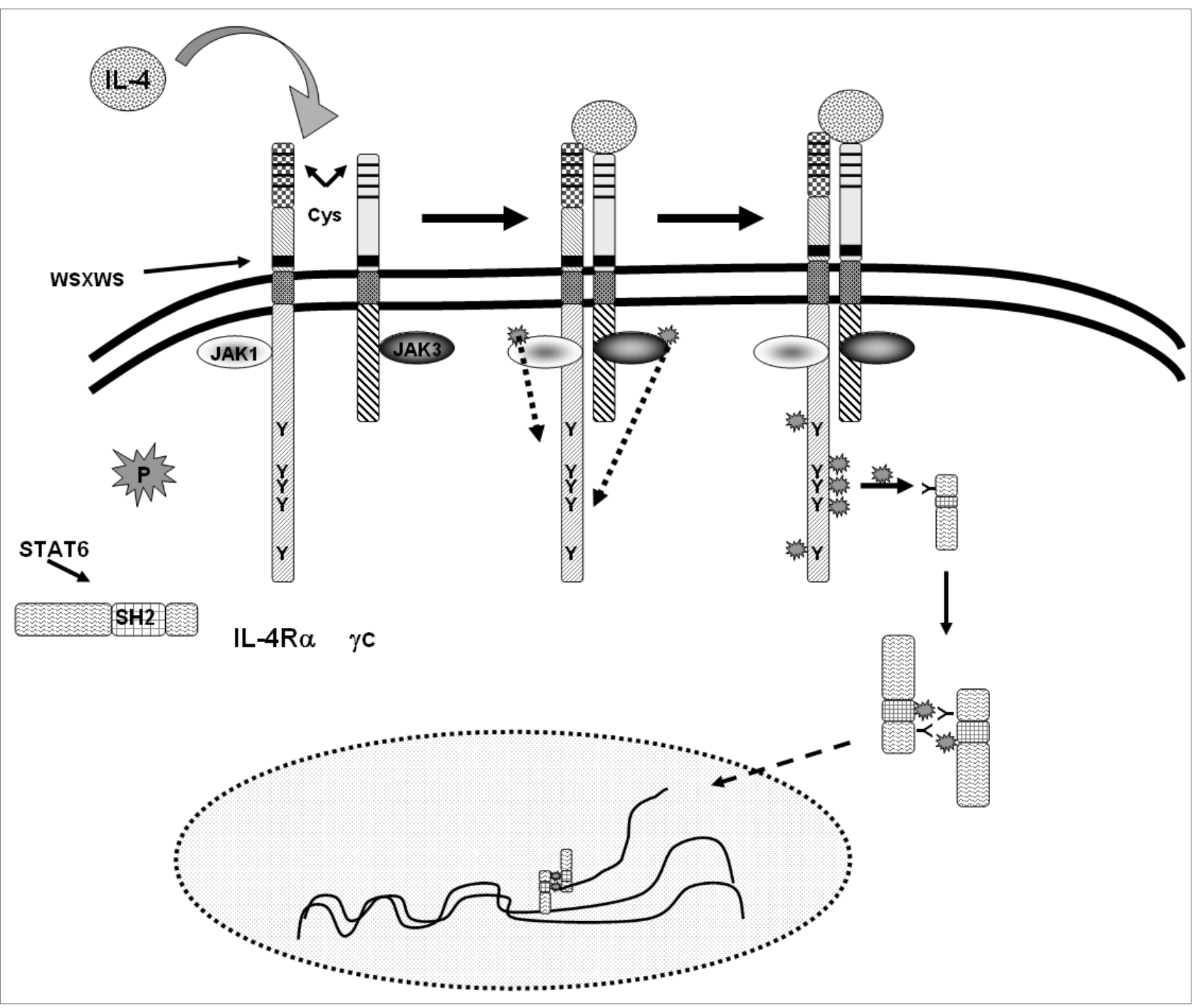

Fig. 3. STAT6 signalling pathway. IL4 binding to receptor activates JAKs, they phosphorylate receptor and STAT6 binds to the activated receptor. STAT6 becomes tyrosine phosphorylated, STAT6 monomers dimerize, tanslocate to the nucleus and bind to GAS elements on target genes - for details see the text. Cys - positionally conserved cysteine residues; WSXWS - motif, that is characteristic for type I cytokine receptors; JAK1 - Janus kinase 1; JAK3 - Janus kinase 3; P - phosphorylation; Y - conserved tyrosine residues; SH2 - SH2 domain of STAT6; IL-4R $\alpha, \gamma c$ - subunits of IL4 receptor

domain of IL-4R $\alpha$, namely Y575, Y603 and Y633 of the human receptor. The thyrosines provide a docking site for the STAT6 which associates with the receptor through its SH2 domain and STAT6 becomes tyroxine phosporylated at conserved Y641. Activated STAT6 monomers dimerize by interaction of phosphorylated Y641 of one monomer and the $\mathrm{SH} 2$ domain of the other monomer. Dimers of STAT subsequently translocate to the nucleus and bind to the GAS elements ( $\gamma$-IFN activated sequence) - in the case of STAT6, TTCN4GAA motifs are recognized ${ }^{30,35}$, reviewed in ${ }^{36,37}$.

\section{POLYMORPHISMS IN STAT6 - IGE LEVEL AND ASTHMA}

Since the first description of the $12 \mathrm{q}$ locus association with asthma or IgE level, and since the discovery of the role of STAT6 in the IL-4 signalling pathway, great attention has been directed to the role of STAT6 polymorphisms on IgE level or asthma development in GWA studies $^{14,16,38}$.

5 'UTR of the gene contains several polymorphisms. The GT repeat polymorphism (rs71802646) was described by Tamura et al. ${ }^{39}$ and contains 7 different alleles, according to the number of GT repeats, ranging in size from $(\mathrm{GT})_{12}$ to $(\mathrm{GT})_{18}$ (ref. $\left.{ }^{39-41}\right)$. In the Indian population, a wider spectrum of GT repeats was observed, from 13 to 24 repeats $^{42}$. The $(\mathrm{GT})_{13}$ allele was much more frequent in children with allergic disease (bronchial asthma, atopic dermatitis and/or food-related anaphylaxis) than controls in the Japanese population $(P=0.0158)$, and $(\mathrm{GT})_{13}$ / $(\mathrm{GT})_{15}$ heterozygotes were strongly associated with those diseases $(P=0.0002)$, but not with $\operatorname{IgE}$ level ${ }^{39}$. Hence the $(\mathrm{GT})_{17}$ repeats showed a trend to increase IgE level in a study of the German population, there was no significant association of GT repeats (13-17 repeats) with IgE levels in asthma phenotype or bronchial hyperresponsiveness 
(after methacholine challenge test) in the Caucasian population. However, a significant effect $(P=0.001)$ was observed on eosinophil count in case of $17 \mathrm{GT}$ repeats ${ }^{40}$. In a study on the British population, the 13 GT repeats were significantly more frequent in atopic asthmatics compared to healthy persons (OR 1.52, 95\% confidence interval 1.02 to $2.28, P=0.027$ ) and conversely, the frequency of 16 GT repeats was significantly increased in persons with non-atopic asthma (OR 0.39, 95\% confidence interval CI 0.17 to $0.92, P=0.018$ ) (ref. ${ }^{41}$ ). Nagarkatti and Ghosh ${ }^{43}$ focused on 5 ' UTR and promoter regions of STAT6 and identified a novel GT repeat region (denoted as $\mathrm{R} 1$ ) in the proximal STAT6 promoter region $(2,3 \mathrm{~kb}$ upstream of the 5 'UTR) and they described the allelic frequency for this polymorphism and for the GT repeats polymorphism in exon 1 (denoted by them as R3 region) in the Indian population. In a subsequent study, Nagarkatti et al. ${ }^{42}$ found a positive association of 16 GT repeats in the R1 locus (OR 1.48, 95\% CI 1.09 to 2.00, but 99\% CI 0.99 to $2.20 ; P=0.01$ ) and $15 \mathrm{GT}$ repeats in the R3 locus with asthma incidence (OR 1.76, Wald's 99\% CI 1.18 to 2.60; $\left.P<10^{-4}\right)$. The 16 GT repeats of R3 were negatively associated with asthma in the Indian population (OR 0.33 , 99\% CI 0.19 to $\left.0.57 ; P<10^{-5}\right)$. They concluded that the R3 region has a greater influence on asthma incidence than the R1 locus ${ }^{42}$.

Gao et al. ${ }^{41}$ analyzed promoter activity of STAT6 and they showed that an allele with 13 GT repeats had a significantly higher transcriptional activity compared to the other alleles (with 12, 16 and 17 GT repeats). However, the promoter activity was not proportional to the number of GT repeats, based on the repeatedly highest promoter activity of (GT) $)_{13}$ allele compared to the other alleles (both longer and shorter). The reciprocal gel shift test obtained a result suggesting more stable binding of the 16 GT repeats allele to the putative nuclear factor(s) compared with the allele with 13 GT repeats. The test for the alleles with 12 and 17 GT repeats gave a similar result; the shorter allele once again had a similar binding property compared to the 13 GT repeats allele. They hypothesized that the allele with longer GT repeats may have a relatively more stable binding to the nuclear factor ${ }^{41}$. These results suggest that GT repeats are important for regulation of gene expression. Buerger et al. showed that the number of intron 1 GT repeats in the gene for epithelial growth factor receptor (EGFR) correlated with the expression of EGFR (ref. ${ }^{44}$ ). The GT repeats are capable of forming a non-B-form of DNA (such as Z-, H- and cruciform DNA), they can be found particularly around promoter regions and therefore they can participate in biological events, such as DNA replication and transcription. According to the close proximity of GT repeats in intron 1 to the translation start of STAT6, Gao et al. ${ }^{41}$ speculated that the repeats may favour formation of a secondary structure (Z-DNA) and thus affect the binding of transcription factors in the vicinity of the exon 1 region. Additionally, other repeat sequences in some gene could influence the transcription activity, but the activity may not be (as seen in case of GT repeats in STAT6 exon 1) proportional to the length of the repeats ${ }^{45-47}$. Therefore the impact of the
GT repeats on transcription could be caused by their binding to inhibitors of transcription, or by forming various non-B form conformation of DNA, or by their combination as hypothesized by Gao et al. ${ }^{41}$.

The 5 ' flanking region of the STAT6 contains several potential regulatory sequences. Duetsch et al. ${ }^{40}$ screened all of the STAT6 exons and adjacent exon/intron junctions and they identified two polymorphisms (among others) in the promoter region. The first (rs2598483) is located 77 bp upstream of CCAAT box, suggested to be an enhancer, and $1771 \mathrm{bp}$ upstream of a prominent transcriptional initiation site. The second lies closer to the site of transcription initiation, 1216 bp upstream of it, and 474 bp downstream of the CCAAT box ${ }^{19}$. Although they are relatively close to the CCAAT box and therefore could putatively have impact on transcription activity of the gene, they were not associated with asthma, peripheral eosinophil cell count or total IgE level in the Caucasian population $^{40,48,49}$.

Duetsch et al. ${ }^{40}$ identified 3 common polymorphisms (SNP) in intron 2 - rs 167769, rs324012 and rs324011. Although none of the SNPs were linked to the occurrence of the asthma phenotype, the rs324011 was associated with total IgE level ${ }^{40,48,49}$. By contrast, the rs324011 was not associated with IgE level in the Finish population ${ }^{50}$. Surprisingly, Huang et al. ${ }^{51}$ described an association between the $\mathrm{C}$ allele (wild type allele) of this polymorphism with penicillin allergy and urticaria, but the polymorphism has no effect on specific IgE level.

Schedel et al..$^{48}$ tried to investigate the putative role of the rs320411 in regulation of STAT6 so they performed a computer analysis of the second intron sequence. The analysis revealed two putative binding sites for transcription factor (TFB) - nuclear factor $\kappa \mathrm{B}(\mathrm{NF}-\kappa \mathrm{B})$. The NF$\kappa \mathrm{B}$ role in IL4 induced responses has been known for a longer time. It binds to specific sequences in promoter regions of target genes, in the vicinity of STAT6 specific sequences. Both the STAT 6 and the NF- $\kappa$ B binding to target sequence is required to induce $\mathrm{IgE}$ production. This event occurs most probably in the protein complex made by other transcription factors, such as PU. $1^{52}$. The two TFB sites in the STAT6 second intron mentioned above are very close to each other and the T allele of rs324011 gives rise to the distal one. The sequence at the site of this SNP is quite strongly conserved among primates ${ }^{48}$. Because the STAT6 synergic cooperates with NF- $\kappa$ B by IL4 mediated IgE production, Schedel and $a .^{48}$ made an assumption that the nucleotide sequence change in this second TFB site caused by rs 324011 could contribute to elevated IgE production. To confirm this hypothesis they performed an in vivo and ex vivo experiment focused on the effect of STAT6 In2 and its rs324011 SNP on STAT6 function $^{23}$. They found that the In 2 itself has a silencing influence on STAT6 promoter activity (and therefore on the STAT6 transcription), no matter if the intron 2 has sense or antisense orientation (in used promoter constructs). This fact indicates that silencing elements are also in the promoter region (approximately $1.1-5.6 \mathrm{~kb}$ before transcription start). This theory supports the observation that the transcription activity of constructs contain- 
ing only promoter (without intron 2 sequence) depends on the length of sequence located before the start of translation. When intron 2 was introduced into the used constructs, there was a great decrease in promoter activity in the presence of the wt allele of rs324011. Contrarily, the $\mathrm{T}$ allele of rs324011 SNP resulted in restoration of potent increase in STAT6 promoter activity - however, this effect was observed only in constructs containing the longest STAT6 promoter sequence (5643 bp). These observations point out to putative physical interaction of intron 2 with promoter region. Allele specific binding of NF- $\kappa \mathrm{B}$ responsible for promoter activity increase was proved by EMSA experiments (electrophoretic mobility shift assay), since NF- $\kappa$ B binding onto specific DNA/ protein complexes was observed only in the presence of the T allele of rs324011.

Schedel et al. ${ }^{23}$ wanted to verify the in silico observation in ex vivo condition, they decided to measure STAT6 mRNA activity in children with asthma. Surprisingly, they revealed two new STAT6 mRNA isoforms containing In 17 or In17+In18 (STAT6d a STAT6e, respectively). They supposed their presence was caused by intron retention or alternative site of translation start. Patients with asthma bearing the TT genotype in rs324011 had a mild, but not significant increase in the known STAT6 form and a significantly increased level of STAT6d and STAT6e mRNA. However, the role of the two isoforms on IgE production is still unclear. Shortly, Schedel et al. confirmed the T allele of rs324011 increased STAT6 promoter activity by creating a new site for NF- $\kappa \mathrm{B}$ specific binding. According to their results, they presumed physical interaction of intron 2 with promoter region and further change of STAT6 $3 \mathrm{D}$ structure or its epigenetic signature caused by NF- $\kappa \mathrm{B}$ binding ${ }^{23}$.

Leung et al. ${ }^{53}$ investigated the effect of STAT6 together with five other candidate genes on asthma occurrence. They assessed the effect of T1309C (rs841718) and C1570T (rs3024974) single nucleotide polymorphisms (SNP) in $17^{\text {th }}$ and $18^{\text {th }}$ introns, respectively, on functional lung parameters and they discovered the C1570T SNP significantly influenced $\mathrm{FEV}_{1}$ decline (spirometric measurements were repeated in one year delay). This SNP, located approximately in the middle of the $18^{\text {th }}$ intron, was not associated with total IgE level in the Chinese population in a previous study of these authors and in a study performed on a Caucasian population of German origin ${ }^{48,54}$. However, a study on another German Caucasian population described a weakly significant effect of the T1309C $(P=0.026)$ and strong effect of $\mathrm{C} 1570 \mathrm{~T}(P=0.007)$ polymorphisms on IgE level ${ }^{40}$. Interestingly, the C1570T SNP was associated with annual FEV1 change ("growth") in Chinese children with asthma ${ }^{53}$.

Hence the 3' UTR could also have an important role in appropriate gene expression by affecting mainly mRNA stability and localisation of the mRNA in the cytoplasm. This region was also screened for polymorphisms with possible effect on asthma disease incidence. Duetsch et al. ${ }^{40}$ studied 5 polymorphisms in this region and found association of 3 ' UTRSNP3 (rs 1059513) with bronchial responsiveness to methacholine challenge and 3 'UTRSNP4 (rs4559) with IgE level. The T allele of the rs4559 SNP was more common in Chinese children with asthma but there was no association of any genotype bearing $\mathrm{T}$ allele with asthma bronchiale or IgE level ${ }^{55}$. In spite of this lack of association for single SNPs in their population, Wang et al. ${ }^{55}$ observed clear interaction of GT repeats in intron 1, C258T (rs4559) and T710C (rs324015) polymorphisms with susceptibility to develop asthma. In a GWAS in the Framingham Heart Study, the rs 1059513 was shown as one of the most significant SNPs associated with IgE dysregulation ${ }^{56}$.

The 2964 G>A SNP (rs324015), identified in the year 2000 in the healthy UK population ${ }^{57}$, is also located in the 3 ' UTR region of the STAT6 and its role in atopy and asthma development was relatively extensively studied. Gao et al. ${ }^{58}$ reported an association of this SNP with mild adult atopic asthma (OR 3.19, 95\% CI 1.40 to $7.08 ; P=0.0043$ ) in the Japanese population. They observed no association of this SNP with either IgE level or marked asthma (groups of children or adults) in the Japanese and British populations. Negoro et al. ${ }^{59}$ described the association of this SNP with IgE level and eosinophil count in Japanese children with atopic eczema and food allergy. Although there was no association with total or specific $\operatorname{IgE}$ in the UK population, the $G$ allele of rs 324015 was significantly more frequent in patients suffering from nut allergy compared to both health controls (without sufficient information about their atopy status) and atopic persons without nut allergy. The GG homozygotes were at increased risk of developing a severe nut allergy reaction $(\mathrm{OR}=3.9$, $95 \%$ confidence interval 1.9-8.3) $\left(\right.$ ref $\left.^{60}\right)$. Conversely, no association was found with atopy or asthma for this SNP in German, Chinese or Finish populations ${ }^{40,50,61}$. In addition, distribution of 2964 G>A SNP was also examined in patients with inflammatory bowel disease and the $G$ allele was significantly more frequent in patients with Crohn disease without variation in the CARD15 ( ref. $^{62}$ ). Therefore, the polymorphisms in 3' UTR of STAT6 may have a rather minor effect on allergic disease development, and their direct impact on STAT6 expression, as suggested by Duetsch et al. ${ }^{40}$, could be excluded.

\section{HAPLOTYPES}

Each polymorphism could have a small effect which may reach statistical significance in samples of thousands of people. Therefore, the association studies of haplotypes assembled from studied SNPs are very helpful because they do not require huge numbers of persons to be examined.

Haplotype analysis of GT repeats in the promoter region and in the first exon of STAT6 (rs71802646) in the Indian population showed that the 16_15 and 17_15 haplotypes (assembled from R1 and R3, respectively) were linked to an elevated total IgE level (OR 1.886, $P=0.001$; OR 2.6284, $P=0.0031$; respectively). In contrast, $17 \_14$, 24_16 and 23_16 haplotypes were negatively associated with total IgE level (OR 0.1007, OR 0.0881, OR 0.0902, respectively, $P<10^{-5}$ for all of the 3 haplotypes) $\left(\right.$ ref. $\left.^{42}\right)$. 
Table 1. Frequency of the most frequent haplotypes from STAT6 SNPs common to studies performed on Czech and German Caucasian populations.

\begin{tabular}{lcccc}
\hline Haplotype & Godava et al. $^{64}$ & Weidinger et al. $^{49}$ & Duetsch et al. $^{40}$ & Schedel et al. $^{48}$ \\
\hline TCA & 43.68 & 37.51 & 42.82 & 36.65 \\
CCG & 26.84 & 26.00 & 15.87 & 26.34 \\
CCA & 20.52 & 25.04 & 23.30 & 13.00 \\
\hline
\end{tabular}

We compared our study ${ }^{64}$ (Czech population) with studies of German populations, and we built haplotypes from STAT6 SNPs common to all of the studies only - rs324011, rs3024974 and rs4559, respectively. Subsequently, we compared frequency of STAT6 SNP haplotypes in our population to frequency of haplotypes in German populations.

Homozygosity for 15 GT repeats of rs 71802646 together with homozygosity for wild type of $2964 \mathrm{G}>\mathrm{A}$ SNP was significantly associated with allergic subjects $(P=0.0382)$ in the Japanese population ${ }^{63}$. Duetsch et al..$^{40}$ analysed the relation of haplotypes (obtained from a combination of 13 examined SNPs) with atopy or asthma in the German population but they did not find any significant association, not even for the two haplotypes containing all alleles of the polymorphisms with weak or significant effects on the examined traits. Weidinger et al. ${ }^{49}$ conducted a study of 6 SNPs spanning the entire STAT6 in the German population and by using the haplotype analysis, they found that the most frequent haplotype was associated with an elevated IgE level for IgE cut-off $100 \mathrm{kU} / 1$ (OR 1.7, 95\% CI 1.11-2.6, $P=0.015)$ and subsequently for the $50^{\text {th }}, 66^{\text {th }}$ and $90^{\text {th }}$ percentiles of IgE level (OR 1.54, $P=0.032$; OR 1.6, $P=0.025$; OR 2.54, $P=0.007$; respectively). Another two haplotypes were found as a significant risk for specific sensitization $(\mathrm{OR}=2.0, P=0.03)$ and asthma development $(\mathrm{OR}=2.17, P=0.01)$, respectively. Schedel et al. ${ }^{48}$ performed the third study of STAT6 polymorphisms on the German Caucasian population, haplotypes were inferred from the 6 SNPs spanning the entire gene. They observed that the most frequent haplotype (haplotype no. 3) was significantly associated with IgE level. In contrast, haplotype no. 4 showed a borderline protective effect against elevation of IgE. We also conducted an association study of STAT6 SNPs with IgE level and asthma on a group of Czech Caucasian children ${ }^{64}$. We did not find any association of single SNP with the examined traits, but the most frequent haplotype (s1 haplotype) in our population was associated with an elevated total IgE level in patients. We compared our results to results of studies performed on the German population ${ }^{40,48,49}$ and we found that the frequency of haplotypes assembled from polymorphisms common to our and German studies were similar (Table 1). According to this observation, we suggested that these STAT6 SNPs have the greatest effect on IgE level and therefore the TCA haplotype alone (built from rs324011, rs3024974 and rs4559 SNPs, respectively) in STAT6 is associated with total IgE elevation.

\section{STAT6 AND EPISTASIS}

According to the theory of epistasis, several SNPs in combination could have an additive effect on gene function. The SNPs may interact with each other in the signalling pathway and this could lead to more than an additive effect, especially in the case of interaction between SNPs of different candidate genes. The effect of simple SNPs or haplotypes built from the SNPs in one gene could be noteworthy, but genes work and interact together in pathways. Therefore the interaction of functionally important polymorphisms in the genes of one pathway may have greater value on dysregulation of the pathway.

Japanese children suffering from atopic dermatitis or food allergy (complicated by another allergy disease such as asthma) with AG genotype for rs324015 SNP (2964 G>A) in combination with AA genotype of IL4R polymorphism (1652 A>G) or TC genotype of IL-4 polymorphism (590C $>\mathrm{T}$ ) were significantly more likely to have an increased eosinophil count or IgE level, respectively ${ }^{59}$. Kabesch et al. ${ }^{13}$ studied 18 SNPs in four genes - STAT6, IL4, IL13 and IL4Ra. For analysis of interaction among these genes, they chose only one SNP per gene because all of the four polymorphisms (rs324011 in STAT6, rs 1805010 in IL4Ra, rs 1800925 in IL13 and rs2243250 in IL4) were previously reported to lead to functionally relevant alterations. They found that combinations of these SNPs in pairs or triplets increased the risk of elevated $\mathrm{IgE}$ or asthma development more potently than did the single allele of the respective SNPs. Risk of developing asthma or elevated serum $\operatorname{IgE}$ was significant in the presence of $\mathrm{T} / \mathrm{T}$ and $\mathrm{G} / \mathrm{T}$ alleles of STAT6/IL13 and IL4Ra/IL4 pair combinations, respectively. Among these combinations, the maximal risk for elevated $\mathrm{IgE}$ was 10.8 times higher $(P=0.02)$ and risk of developing asthma was 16.8 times higher compared to the maximal effect of a single polymorphism (1.73 times higher in case of STAT6 SNP). Although the risk of developing atopic asthma was not included in the statistical correlation, the authors commented that rs 1800925 (in IL-13) and rs324011 (in STAT6) seemed to be overrepresented in SNP combinations conferring the greatest risk for asthma and/or elevated IgE (in other words for atopic asthma). Wu et al. ${ }^{65}$ performed analysis of 8 SNPs in 5 key susceptibility genes (STAT6, IL4, IL4Ra, ILI3 and CD14). They discovered significant interaction of rs324011 in STAT6 
and 5 of the other loci on asthma development in children. Li et al. ${ }^{66}$ observed significant gene-gene interaction between STAT6 (rs324015), IFNG and STAT4 on risk of asthma development in the Chinese population.

\section{STAT6 AND EPIGENETICS}

In recent years, researchers have pointed out that environmental and epigenetic factors have an important impact on the final atopy or asthma phenotype ${ }^{67}$. The histone acetylation and DNA methylation are main epigenetic mechanisms ${ }^{67,68}$. For example, the Th2 cells showed complete demethylation in the RHS7 (rad50 hypersensitive site 7) of the Th2 LCR (locus control region) due to almost complete methylation (96\%) of the third $\mathrm{CpG}$ residue of RHS7 in naïve T cells and this occurred in a STAT6-dependent manner ${ }^{69}$. Furthermore, the parental origin of atopy or asthma has been discussed for a long time. Transmission of atopy from the maternal line was observed for locus 11q13 (ref. ${ }^{70}$ ). Infants with elevated cord blood IgE had a higher risk of developing asthma and elevated $\mathrm{IgE}$ in cord blood was associated with maternal atopy ${ }^{3}$.

Kim et al. ${ }^{71}$ examined the STAT6 promoter and reported that its hypermethylation leads to repression of STAT6 expression. They also found that the 13 GT repeats in exon 1 of STAT6 appeared more frequently than 15 GT repeats in patients with asthma and rheumatoid arthritis than in controls. Subsequently, they performed expression analysis of these repeats in constructs containing minimal functional promoter. The expression was significantly higher than in the case of promoter alone, but there was no significant difference in expression between those GT repeats. This result was in contradiction to the results of Gao et al. ${ }^{41}$ so they concluded, that DNA hypermethylation rather than promoter polymorphisms influences STAT6 expression. However, Kim et al. ${ }^{71}$ used constructs with a much shorter part of promoter compared to the report of Gao et al..$^{41}$ and so interaction of GT repeats polymorphism with the distal part of the promoter could not be excluded. Moreover, Schedel et al. ${ }^{23}$ reported the above interaction of STAT6 intron 2 with the distal region of STAT6 promoter and proved the influence of rs324011 polymorphism on STAT6 expression.

At the present time the maternal influence is believed to have the greatest influence on atopy or asthma development. In an association study of STAT6 polymorphisms on the Czech population, we also attempted to examine the role of parental origin of STAT6 haplotypes on total IgE levels in the patients. Surprisingly, we observed that haplotype associated with elevation of total $\operatorname{IgE}$ levels was significantly more often inherited from fathers and showed a higher tendency to increase the total IgE level than did the haplotype transmitted from mothers. This difference in IgE level could point to a distinct imprinting pattern of the haplotype. Some genes are able to fully or partially escape epigenetic reprogramming during prenatal development ${ }^{67,72}$ and thus they can preserve their special DNA methylation pattern. Moreover, the specific epigenetic pattern can be transmitted to the descendant, in other words the epigenetic changes may be transmitted transgenerationally ${ }^{72,73}$. These processes could at least partially explain the difference in total IgE levels. We hypothesize that paternally inherited s1 haplotype by itself confers a greater risk to the elevation of total IgE. This effect is modulated in utero by the mother, as e.g. maternal behaviour and diet could influence the epigenetic programming of the fetus ${ }^{72}$.

\section{CONCLUSION}

STAT6 has a crucial role in the IL-4/IL-13 signalling pathway and previous studies have showed linkage of STAT6 to atopy or asthma. Association studies searching for relation of polymorphisms in STAT6 with IgE level or asthma discovered a few polymorphisms significantly associated with examined traits. All of these polymorphisms are in introns or in untranslated regions of STAT6 and therefore they affect STAT6 expression rather then the aminoacid sequence. Only two polymorphisms showed repeatedly significant clinical association and/or functional effect on STAT6 function (GT repeats in exon 1 and rs324011 polymorphism in intron 2). The haplotype studies showed that the effect of STAT6 polymorphisms cumulates in haplotypes and according to studies on the Caucasian population (Czech and German) there is obviously one potent haplotype build from the 3 polymorphisms. STAT6 gene does not work alone, it cooperates with other genes in IL-4 / IL-13 signalling pathway therefore the study of gene - gene interactions (with regard to relevant polymorphisms of those genes) is more important than examination of the only particular polymorphisms in a single gene. Research of methylation or generally imprinting pattern of regulatory region of STAT6 and other genes is also very interesting due to their effect on gene expression. Furthermore, influencing gene expression represents a very exciting field for research with a promising perspective for targeted therapy, as was outlined by Darcan-Nicolaisen et al. ${ }^{74}$ in a study demonstrating inhibition of allergy inflammation and hyperreactivity by STAT6 siRNA in mice.

\section{CONFLICT OF INTEREST STATEMENT}

Author's conflict of interest disclosure: None declared.

\section{REFERENCES}

1. Jarvis D, Burney P. The epidemiology of allergic disease. BMJ 1998;316(7131):607-10.

2. Shapira SK, Vercelli D, Jabara HH, Fu SM, Geha RS. Molecular analysis of the induction of immunoglobulin $E$ synthesis in human $B$ cells by interleukin 4 and engagement of CD40 antigen. J Exp Med 1992;175(1):289-92.

3. Magnusson CG. Cord serum IgE in relation to family history and as predictor of atopic disease in early infancy. Allergy 1988;43:241-51. 
4. Liu CA, Wang CL, Chuang H, Ou CY, Hsu TY, Yang KD. Prenatal prediction of infant atopy by maternal but not paternal total lgE levels. J Allergy Clin Immunol 2003;112:899-904.

5. Yang KD, Ou CY, Hsu TY, Chang JC, Chuang H, Liu CA, Liang HM., Kuo HC, Chen RF, Huang EY. Interaction of maternal atopy, CTLA-4 gene polymorphism and gender on antenatal immunoglobulin $\mathrm{E}$ production. Clinical and Experimental Allergy 2007;37:680-7.

6. Canfield SM, Jacobson JS, Perzanowski MS, Mellins RB, Zemble RM, Cheb GL, Goldstein IF. Total and specific IgE associations between New York City Head Start children and their parents. J Allergy Clin Immunol 2008;121:1422-7.

7. Cookson WO, Young RP, Sandford AJ, Moffatt MF, Shirakawa T, Sharp PA, Faux JA, Julier C, Nakumuura Y. Maternal inheritance of atopic IgE responsiveness on chromosome 11q. Lancet 1992;340:381-4.

8. Raby BA, Soto-Quiros ME, Avila L Lake SL, Murény A, Liang C, Fournier E, Spesny M, Sylvia JS, Verner A, Hudson TJ, Klanderman BJ, Freimer NB, Silverman EK, Celedón JC. Sex-specific linkage to total serum immunoglobulin $E$ in families of children with asthma in Costa Rica. Human Molecular Genetics 2007; 16:243-53.

9. Weidinger S, Gieger C, Rodriguez E, Baurecht H, Mempel M, Klopp $\mathrm{N}$, Gohlke H, Wagenpfeil S, Ollert M, Ring J, Behrendt H, Heinrich J, Novak N, Bieber T, Krämer U, Berdel D, von Berg A, Bauer CP, Herbarth O, Koletzko S, Prokisch H, Mehta D, Meitinger T, Depner $M$, von Mutius E, Liang $L$, Moffatt $M$, Cookson W, Kabesch M Wichmann HE, Illig T. Genome-Wide Scan on Total Serum IgE Levels Identifies FCER1A as Novel Susceptibility Locus. PLoS Genet 2008;4(8):e1000166. doi: 10.1371/journal.pgen.100016

10. Marsh DG, Neely JD, Breazeale DR, Ghosh B, Freidhoff LR, EhrlichKautzky E, Schou C, Krishnaswamy G, Beaty TH. Linkage analysis of IL-4 and other chromosome 5q31.1 markers and total serum immunoglobulin E concentrations. Science 1994;264(5162):1152-6.

11. The collaborative study on the genetics of asthma. A genome-wide search for asthma susceptibility loci in ethnically diverse populations. Nat Genet 1997;15:389-92.

12. Deichmann KA, Heinzmann A, Forster J, Dischinger S, Mehl C, Brueggenolte E, Hildebrandt F, Moseler M, Kuehr J. Linkage and allelic association of atopy and markers flanking the IL-4-receptor gene. Clin Exp Allergy 1997;28(2):151-5.

13. Kabesch M., Schedel M, Carr D, Woitsch B, Fritzsch Ch, Stephan K, Weiland SK, Murous E. IL-4/IL-13 pathway genetics strongly influence serum IgE levels and childhood asthma. J Allergy Clin Immunol 2006; 117:269-74.

14. Barnes KC, Neely JD, Duffy DL, Freidhoff LR, Breazeale DR, Schou C, Naidu RP, Levett PN, Renault B, Kucherlapati R, lozzino S, Ehrlich E, Beaty TH, Marsh DG. Linkage of asthma and total serum IgE concentration to markers on chromosome 12q: evidence from AfroCaribbean and Caucasian populations. Genomics 1996;37:41-50.

15. Nickel R, Wahn U, Hizawa N, Maestri N, Duffy DL, Barnes KC, Beyer K, Forster J, Bergmann R, Zepp F, Wahn V, Marsh DG. Evidence for linkage of chromosome 12q15-q24.1 markers to high total serum $\lg$ E concentrations in children of the German Multicenter Allergy Study. Genomics 1997;46:159-62.

16. Barnes KC, Freidhoff LR, Nickel R, Chiu YF, Juo SH, Hizawa N, Naidu RP, Ehrlich E, Duffy DL, Schou C, Levett PN, Marsh DG, Beaty TH.: Densemapping of chromosome 12q13.12-q23.3 and linkage to asthma and atopy. J Allergy Clin Immunol 1999;104:485-91.

17. Hou J, Schindler U, Henzel WJ, Ho TC, Brasseur M, McKnight SL. An interleukin-4-induced transcription factor: IL-4 stat. Science 1994;265:1701-6.

18. Quelle FW, Shimoda K, Thierfelder W, Fischer C, Kim A, Ruben SM, Cleveland $J$, Pierce JH, Keegan AD, Nelms K, Paul WE, Ihle JN. Cloning of murine Stat6 and human Stat6, Stat proteins that are tyrosine phosphorylated in responses to II-4 and II-3 but are not required for mitogenesis. Molecular and cellular biology 1995;15:333643.

19. Patel BK, Keck CL, O'Leary RS, Popescu NC, LaRochelle WJ. Localization of the human stat6 gene to chromosome 12 q13.3q14.1, a region implicated in multiple solid tumors. Genomics 1998:52:192-200.

20. Patel BK,Wang LM, Lee CC, Taylor WG, Pierce JH, LaRochelle WJ. Stat6 and Jak1 are common elements in platelet-derived growth factor and interleukin-4 signal transduction pathways in NIH 3T3 fibroblasts. J Biol Chem 1996;271:22175-82.
21. Patel BK, Pierce JH, LaRochelle WJ. Regulation of interleukin 4-mediated signaling by naturally occurring dominant negative and attenuated forms of human Stat6. Proc Natl Acad Sci U S A 1998;95:172-7.

22. Hebenstreit D, Wirnsberger G, Horejs-Hoeck J, Duschl A. Signaling mechanisms, interaction partners, and target genes of STAT6. Cytokine Growth Factor Rev 2006;17(3):173-88.

23. Schedel M,Frei R, Bieli Ch, Cameron L, Adamski J, Lauener R and Kabesch M. An IgE-associated polymorphism in STAT6 alters NF-kB binding, STAT6 promoter activity, and mRNA expression. J Allergy Clin Immunol 2009;124(3):583-9.

24. Wurster AL, Tanaka T, Grusby MJ. The biology of Stat4 and Stat6. Oncogene 2000;19(21):2577-84.

25. Xu X, Sun YL, Hoey T. Cooperative DNA binding and sequence-selective recognition conferred by the STAT amino-terminal domain. Science 1996;273(5276):794-7.

26. Vinkemeier U, Cohen SL, Moarefi I, Chait BT, Kuriyan J, Darnell JE Jr. DNA binding of in vitro activated Stat 1 alpha, Stat 1 beta and truncated Stat 1: interaction between $\mathrm{NH} 2$-terminal domains stabilizes binding of two dimers to tandem DNA sites. EMBO J 1996;15(20):5616-26.

27. Musacchio A, Gibson T, Lehto VP, Saraste M. SH3, an abundant protein domain in search of a function. FEBS Lett 1992;307:55-61.

28. Morton CJ, Campbell ID. SH3 domains. Molecular 'Velcro'. Curr Biol 1994;4:615-7.

29. Pawson T, Gish GD. SH2 and SH3 domains: from structure to function. Cell 1992;71:359-62.

30. Mikita T, Daniel C, Wu P, Schindler U. Mutational analysis of the STAT6 SH2 domain. J Biol Chem 1998;273(28):17634-42.

31. Litterst CM, Pfitzner E. Transcriptional activation by STAT6 requires the direct interaction with NCoA-1. J Biol Chem 2001;276(49):4571321.

32. Delphin S, Stavnezer J. Characterization of an interleukin 4 (IL-4) responsive region in the immunoglobulin heavy chain germline epsilon promoter: regulation by NF-IL-4, a C/EBP family member and NF-kappa B/p50. J Exp Med 1995;181(1):181-92.

33. Shimoda K, van Deursen J, Sangster MY, Sarawar SR, Carson RT, Tripp RA, Chu C, Quelle FW, Nosaka T, Vignali DA, Doherty PC, Grosveld G, Paul WE, Ihle JN. Lack of IL-4-induced Th2 response and IgE class switching in mice with disrupted Stat6 gene. Nature 1996;380(6575):630-3.

34. Kaplan MH, Schindler U, Smiley ST, Grusby MJ. Stat6 is required for mediating responses to IL-4 and for development of Th2 cells. Immunity 1996;4(3):313-9.

35. Mikita T, Campbell D, Wu P, Williamson K, Schindler U. Requirements for interleukin-4-induced gene expression and functional characterization of Stat6. Mol Cell Biol 1996;16(10):5811-20.

36. Leonard WJ, O'Shea JJ. Jaks and STATs: Biological implications. Annu Rev Immunol 1998;16:293-322.

37. Chatila TA. Interleukin-4 receptor signaling pathways in asthma pathogenesis. Trends Mol Med 2004;10(10):493-9.

38. Wjst M, Fischer G, Immervoll T, Jung M, Saar K, Rueschendorf F, Reis A, Ulbrecht M, Gomolka M, Weiss EH, Jaeger L, Nickel R, Richter K, Kjellman NI, Griese M, von Berg A, Gappa M, Riedel F, Boehle M, van Koningsbruggen S, Schoberth P, Szczepanski R, Dorsch W, Silbermann M, Wichmann HE. A genome-wide search for linkage to asthma. German Asthma Genetics Group. Genomics 1999;15;58(1): $1-8$.

39. Tamura K, Arakawa H, Suzuki M, Kobayashi Y, Mochizuki H, Kato M Tokuyama K, Morikawa A. Novel dinucleotide repeat polymorphism in the first exon of the STAT- 6 gene is associated with allergic diseases. Clin Exp Allergy 2001;31(10):1509-14.

40. Duetsch G, Illig T, Loesgen S, Rohde K, Klopp N, Herbon N, Gohlke H, Altmueller J, Wjst M. STAT6 as an asthma candidate gene: polymorphism-screening, association and haplotype analysis in a Caucasian sib-pair study. Hum Mol Genet 2002;11(6):613-21.

41. Gao PS, Heller NM, Walker W, Chen CH, Moller M, Plunkett B, Roberts $\mathrm{MH}$, Schleimer RP, Hopkin JM, Huang SK. Variation in dinucleotide (GT) repeat sequence in the first exon of the STAT6 gene is associated with atopic asthma and differentially regulates the promoter activity in vitro. J Med Genet 2004;41(7):535-9.

42. Nagarkatti R, B-Rao C, Vijayan V, Sharma SK, Ghosh B. Signal transducer and activator of transcription 6 haplotypes and asthma in the Indian population. Am J Respir Cell Mol Biol 2004;31(3):317-21. 
43. Nagarkatti R, Ghosh B. Identification of single-nucleotide and repeat polymorphisms in two candidate genes, interleukin 4 receptor (IL4RA) and signal transducer and activator of transcription protein 6 (STAT6), for Th2-mediated diseases. J Hum Genet 2002;47(12):684-7.

44. Buerger H, Gebhardt F, Schmidt H, Beckmann A, Hutmacher K, Simon R, Lelle R, Boecker W, Brandt B. Length and loss of heterozygosity of an intron 1 polymorphic sequence of egfr is related to cytogenetic alterations and epithelial growth factor receptor expression. Cancer Res 2000;60(4):854-7.

45. Travers AA, Klug A. Bending of DNA in Nucleoprotein Complexes. In: Cozzarelli NR, Wang JC, editors. DNA topology and its biologica effects. New York: Cold Spring Habour Laboratory Press; 1990. p. 57-106.

46. Searle S, Blackwell JM. Evidence for a functional repeat polymorphism in the promoter of the human NRAMP1 gene that correlates with autoimmune versus infectious disease susceptibility. J Med Genet 1999;36(4):295-9.

47. Shimajiri S, Arima N, Tanimoto A, Murata Y, Hamada T, Wang KY, Sasaguri Y. Shortened microsatellite d(CA)21 sequence down-regulates promoter activity of matrix metalloproteinase 9 gene. FEBS Lett 1999;455(1-2):70-4.

48. Schedel M, Carr D, Klopp N, Woitsch B, Illig T, Stachel D, Schmid I, Fritzsch C, Weiland SK, von Mutius E, Kabesch M. A signal transducer and activator of transcription 6 haplotype influences the regulation of serum IgE levels. J Allergy Clin Immunol 2004;1 14(5):1100-5.

49. Weidinger S, Klopp N, Wagenpfeil S, Rümmler L, Schedel M, Kabesch M, Schäfer T, Darsow U, Jakob T, Behrendt H, Wichmann HE, Ring J, Illig T. Association of a STAT 6 haplotype with elevated serum IgE levels in a population based cohort of white adults. J Med Genet 2004;41(9):658-63.

50. Pykäläinen $M$, Kinos R, Valkonen S, Rydman P, Kilpeläinen $M$, Laitinen LA, Karjalainen J, Nieminen M, Hurme M, Kere J, Laitinen T and Riitta Lahesmaa R. Association analysis of common variants of STAT6, GATA3, and STAT4 to asthma and high serum IgE phenotypes. J Allergy Clin Immunol 2005;115(1):1100-5.

51. Huang CZ, Zou D, Yang J, Qiao HL. Polymorphisms of STAT6 and specific serum IgE levels in patients with penicillin allergy. Int J Clin Pharmacol Ther 2012;50(7):461-7.

52. Stütz AM and Woisetschläger M. Functional synergism of STAT6 with either NF-kB or PU.1 to mediate IL-4-induced activation of IgE germline gene transcription. The Journal of Immunology 1999;163:438391.

53. Leung TF, Chan IH, Wong GW, Li CY, Tang NL, Yung E and Lam CW Association between candidate genes and lung function growth in Chinese asthmatic children. Clinical and Experimental Allergy 2007;37:1480-6.

54. Li CY, Leung TF, Tang NL, Wong GW, Sung YM, Chan IH, Lam CW Fok TF. STAT6 in17SNP1 and in18SNP1 polymorphisms are not as sociated with asthma or atopy in Chinese children. J Allergy Clin Immunol 2004;113(Suppl):S205.

55. Wang Q, Bai XT, Xu DQ, Li H, Xu CY, Fang JL. Association of polymorphisms of STAT6 and SO(2) with Chinese childhood asthma: a case-control study. Biomed Environ Sci 2011;24(6):670-7.

56. Granada M, Wilk JB, Tuzova M, Strachan DP, Weidinger S, Albrecht E, Gieger C, Heinrich J, Himes BE, Hunninghake GM, Celedón JC, Weiss ST, Cruikshank WW, Farrer LA, Center DM, O'Connor GT. A genomewide association study of plasma total IgE concentrations in the Framingham Heart Study. J Allergy Clin Immunol 2012;129(3):840-5.

57. Amoli M, Ollier WE, Hajeer AH. A novel PCR-RFLP assay for the detection of a polymorphism in the 3' of STAT6 gene. Genes Immun 2000;1(5):349-50.

58. Gao PS, Mao XQ, Roberts MH, Arinobu Y, Akaiwa M, Enomoto T, Dake Y, Kawai M, Sasaki S, Hamasaki N, Izuhara K, Shirakawa T, Hopkin JM.
Variants of STAT6 (signal transducer and activator of transcription 6) in atopic asthma. J Med Genet 2000;37(5):380-2.

59. Negoro T, Orihara K, Irahara T, Nishiyama H, Hagiwara K, Nishida R, Takagi H, Satoh K, Yamamoto Y, Shimizu S, Hagiwara T, Ishii M, Tanioka T, Nakano Y, Takeda K, Yoshimura I, likura Y, Tobe T. Influence of SNPs in cytokine-related genes on the severity of food allergy and atopic eczema in children. Pediatr Allergy Immunol 2006;17(8):58390.

60. Amoli MM, Hand S, Hajeer AH, Jones KP, Rolf S, Sting C, Davies BH, Ollier WE. Polymorphism in the STAT6 gene encodes risk for nut al lergy. Genes Immun 2002;3(4):220-4.

61. Wu B, Li YF, Xiong HY, Zhang L. Case- control study of STAT6 gene polymorphisms for asthma in Chongqing. Immunology Journal 2006;22(3):308-10.

62. Klein W, Tromm A, Folwaczny C, Hagedorn M, Duerig N, Epplen J, Schmiegel W, Griga T. The G2964A polymorphism of the STAT6 gene in inflammatory bowel disease. Dig Liver Dis 2005;37(3):159-61.

63. Tamura K, Suzuki M, Arakawa H, Tokuyama K, Morikawa A. Linkage and association studies of STAT6 gene polymorphisms and allergic diseases. Int Arch Allergy Immunol 2003;131(1):33-8.

64. Godava M, Kopriva F, Bohmova J, Vodicka R, Dusek L, Cvanova M, Muzik J, Markova M, Schneiderova E, Vrtel R. Association of STAT6 and ADAM33 single nucleotide polymorphisms with asthma bronchiale and IgE level and its possible epigenetic background. Biomed Pap Med Fac Univ Palacky Olomouc Czech Repub 2012;156(3):23647.

65. Wu X, Li Y, Chen Q, Chen F, Cai P, Wang L, Hu L. Association and gene-gene interactions of eight common single-nucleotide polymorphisms with pediatric asthma in middle china. J Asthma 2010;47(3):238-44.

66. LiY, Wu B, Xiong H, Zhu C, Zhang L. Polymorphisms of STAT-6, STAT-4 and IFN-gamma genes and the risk of asthma in Chinese population. Respir Med 2007;101(9):1977-81.

67. Martino DJ, Prescott SL. Silent mysteries: epigenetic paradigms could hold the key to conquering the epidemic of allergy and immune disease. Allergy 2010;65:7-15.

68. Biel M, Wascholowski V, Giannis A. Epigenetics - An epicenter of gene regulation: histones and histone-modifying enzymes. Angew Chem Int Ed Engl 2005;44:3186-216.

69. Kim ST, Fields PE, Flavell RA. Demethylation of a specific hypersensitive site in the Th2 locus control region. Proc Natl Acad Sci USA 2007;104:17052-7.

70. Cookson WOCM, Young RP, Sandford AJ, Moffatt MF, Shirakawa T, Sharp PA, Faux JA, Julier C, Le Souef PN, Nakumura Y, Lathrop GM, Hopkin JM. Maternal inheritance of atopic IgE responsiveness on chromosome 11q. Lancet 1992;340:381-4.

71. Kim EG, Shin HJ, Lee CG, Park HY, Kim YK, Park HW, Cho SH, Min KU, Cho ML, Park SH, Lee CW. DNA methylation and not allelic variation regulates STAT6 expression in human T cells. Clin Exp Med 2010;10(3):143-52.

72. Dolinoy DC, Das R, Weidman JR, Jirtle RL. Metastable epialleles, imprinting, and the fetal origins of adult diseases. Pediatr Res 2007;61:30R-37R.

73. Rakyan VK, Chong S, Champ ME, Cuthbert PC, Morgan HD, Luu KV Whitelaw E. Transgenerational inheritance of epigenetic states at the murine Axin $(\mathrm{Fu})$ allele occurs after maternal and paternal transmission. Proc Natl Acad Sci USA 2003;100:2538-43.

74. Darcan-Nicolaisen Y, Meinicke H, Fels G, Hegend O, Haberland A, Küh A, Loddenkemper C, Witzenrath M, Kube S, Henke W, Hamelmann E. Small interfering RNA against transcription factor STAT6 inhibits allergic airway inflammation and hyperreactivity in mice. J Immunol 2009;182(12):7501-8 